Short Note

\title{
How good are the ecological assumptions and predictions made in the past? Insights from a dynamic modelling approach applied to changing landscapes
}

\author{
Mário Santos*, Sara Silva, Rita Bastos, Diogo Carvalho, João Alexandre Cabral \\ Laboratory of Applied Ecology, CITAB - Centre for the Research and Technology of Agro-Environment and Biological Sciences, Universidade de Trás-os-Montes e Alto \\ Douro, 5000-911 Vila Real, Portugal
}

\section{A R T I C L E I N F O}

\section{Keywords:}

Passerines

Landscape

Stochastic dynamic methodology

Ecological indicators

Ecological models' evaluation

\begin{abstract}
A B S T R A C T
Worldwide landscape changes and the uncertainty about its impacts on species abundances, distributions and on ecosystems structure and functioning, have been increasing the value of modelling tools in a very obvious way. Thirteen years ago, the first holistic stochastic dynamic methodology (StDM) application was published (Ecological Indicators 3(4), 285-303 by Santos and Cabral (2004)) intended for predicting ecological indicators trends in face of realistic scenarios of land use/land cover changes. The application of this StDM framework provided some basis to simulate landscape changes and predict the subsequent response of pertinent ecological indicators. Nevertheless, the results reliability could only be evaluated with subsequent independent information checking. In this work, based on independent data obtained thirteen years after, we compare the simulated land use changes and predicted responses of the selected ecological indicators with the respective real trends. The comparisons made confirmed that the implemented scenario was realistic and the ecological indicators' response mostly accurate. This allowed for demonstrating the proposed frameworks potential and its use in landscape planning and managing of agro-environmental measures. Our approach also provides a promising and intuitive baseline to support risk assessments for land use changes, derived from ecological models linked with ecological monitoring, crucial to guide decision makers and environmental managers.
\end{abstract}

\section{Introduction}

In lieu of technical and political decision, modelling tools can be very useful to predict the outcome of alternative scenarios, guiding current management options from expected future targets and simulating conditions that are difficult or impossible to understand otherwise (e.g., Schmolke et al., 2010; Santos et al., 2013). Ecological models contain the essential characteristics for solving problems and enhanced ecological studies by creating quantitative simulations and predictions that simultaneously attempt to capture the structure and composition of ecosystems (Jørgensen, 2008). Following the rapid development of computing technology, detailed ecological simulations have become more available. Albeit ecological models have been used in a wide variety of applications related to ecosystem functioning (e.g., Evans et al., 2013) they are usually considered "academic" and in many ways unreliable, i.e., unable to describe, in a comprehensible and "realistic" way, the structural changes when ecosystem conditions are substantially altered (Rykiel, 1996). Consequently, the evaluation of the assumptions and parameters of a model, but mostly the evaluation of the predicted results is critical for assuring modelling credibility and "real world" applicability (Schmolke et al., 2010).

Dynamic and spatially explicit dynamic models designed to predict future landscape patterns and trends could support decision-making for integrated assessments of socio-ecological impacts on biodiversity, namely the influence of internal processes under scenarios induced by external drivers (Santos et al., 2013). These type of models are increasingly considered essential to strategic spatial prioritisation and planning in highly dynamic socio-ecological systems such as agricultural landscapes (e.g., Lomba et al., 2015; Santos et al., 2016b). Southern European countries hold areas of complex agricultural landscapes that are considered significant hotspots of biodiversity (Bugalho et al., 2011; Lomba et al., 2015). Nevertheless, current multifactorial changes occurring in these landscapes, induced either by agricultural intensification or abandonment (e.g., Van Eetvelde and Antrop, 2004), result in large-scale modifications on habitat composition and fragmentation. These changes may imply serious risks for the biodiversity, ecosystem integrity and services of actual socio-ecological systems (e.g., Santos et al., 2016b). The combined influence of land use/land cover changes (LUCC) on passerine richness functional guilds (FG) at the "Terra Quente Transmonta" agricultural landscape (Northern Portugal),

\footnotetext{
* Corresponding author.

E-mail address: mgsantos@utad.pt (M. Santos).
} 
considered key ecological indicators of biodiversity and integrity, was assessed by Santos and Cabral (2004). That work proposed a novel spatio-temporal modelling methodology, the stochastic dynamic methodology (StDM), in order to predict relevant ecological trends in changing landscapes. The StDM is a hybrid modelling protocol combining statistical and dynamic modelling with geostatistical techniques to address complex spatially-explicit emergent problems, from the individual habitat patch to the whole landscape context (e.g., Santos et al., 2013, 2016a). While the parameters of the dynamic model within StDM can be calibrated directly from field knowledge of ecosystem characteristics and bibliographic information (ecologically driven) others, namely the holistic parameters, have to be estimated using statistical algorithms. The statistical parameters, if sustained by a database that includes representative gradients, emerge from spatiotemporal ecosystem properties, might be used for simulation and prediction. This methodology minimizes drawbacks linked with model construction, such as parameterization and complexity, since part of the variables and parameters result from statistical estimation (Santos et al., 2013, 2016a). Explicitly, the response variables emerging from the statistical analysis correspond to the core state variables under study while the explanatory variables are the pertinent environmental factors (ecological-driven). The StDM framework has been successfully tested in several types of ecosystems affected by gradients of change, namely in agroecosystems (Santos et al., 2013, 2016a).

Santos and Cabral (2004) also stated that the evaluation of the overall methodology and results, namely the simulated trends in Land use/Land cover (LULC) and the ecological indicators responses could only be achieved using chronosequential data. In order to evaluate the StDM credibility in simulating landscape changes and the consequent ecological responses, as published thirteen years ago, the objectives of the present demonstration were to: (1) compare the predicted and current real landscapes, as well as the respective composition of passerines' functional guilds (FG); (2) discuss concepts of the stochastic dynamic methodology and possibilities for depicting the consequences of alternative landscape scenarios on ecological integrity; and (3) explain the interest and feasibility of using the StDM framework in guiding rural landscape management challenges and policy options.

\section{Material and methods}

\subsection{Study area and simulated scenario}

Field work associated to the model simulations performance evaluation was carried out in the study area described by Santos and Cabral (2004): "Terra Quente Transmontana" (Mesomediterranean thermoclimatic belt and Carpetano-Leonese biogeographic region - http://www.globalbioclimatics. org/form/maps.htm) region $\left(41^{\circ} 30^{\prime} \mathrm{N}, 7^{\circ} 10^{\circ} \mathrm{W}\right)$, located in north-eastern Portugal (Appendix A). A typical mixture of olive and almond orchards, cereal fields and fallow land, cistus sp. and cytisus sp. shrublands, cork oak woodlands dominated the landscape (Appendix A). The main LUCC predicted were the decrease in areas of cereal and fallow and the increase of areas occupied by olive and almond orchards (Santos and Cabral, 2004). Additionally, the landscape simulated trends predicted a change in the passerine functional guilds' richness, namely arboreal guilds' richness was expected to increase while the pseudo-steppe guilds' richness was expected to decrease. The model conceptualization and the characterization details of the study area are available in Appendixes E-G.

\subsection{Passerine point-counts and land use/land cover monitoring}

Twenty-two 25 ha $(500 \mathrm{~m} \times 500 \mathrm{~m})$ plots were surveyed once during May and June of 2017, for monitoring passerines and fitting together passerine functional guilds (FG) - bird species were identified using $10 \mathrm{~min}$ unlimited-radius point count until $5 \mathrm{~h}$ after sunrise under appropriate weather conditions; bird species were convened in guilds in accordance with preferential diets and habitats using reference information. Each plot was monitored for assessing LULC in 2001/2002 and 2017, considering information provided by the Corine Land Cover (CLC) (http://land.copernicus.eu/pan-european/corine-landcover), Google Earth sequential images (https://www.google.com/ intl/pt-PT/earth/) and confirmed in 2017 by specific field works oriented towards this purpose. LULC were classified as olive and almond orchards (Ola), shrublands (Shr), cereals and fallow (Cfa), pastures (Pas), fallow land (FAL), vegetable gardens (Veg), vineyards (Vin), fruit orchards (Fru), cork-oak woodlands (Cor), riverine woods (Riv), other woods (Oth) and urbanised areas (Urb) (Appendix B).

\subsection{Simulating land use/land cover trends and predicting functional guilds' richness for 2017}

Using as starting point the original estimated LULC values for each plot in 2001 and considering the landscape trends simulated by Santos and Cabral (2004), i.e., an increase in olive and almond orchards (Ola) at the expense of cereals and fallows (Cfa) (Appendixes E-G), dynamic projections of LULC for 2017 were obtained (Model_LULC). Alongside the model simulations for the FG richness responses were also considered for 2017 (Model_FG) (see also Appendixes E-G).

\subsection{StDM framework performance}

The real data of LULC and FG richness recorded in 2017 (Real_LULC and Real_FG, respectively) were used for assessing the StDM simulations performance (Section 2.2). For this, statistical differences between each variable simulated (Model_LULC and Model_FG) and the respective real data (Real_LULC and Real_FG) were compared by using the Wilcoxon signed rank test (Wilcoxon, 1945). Results were considered accurate if the simulated and real data were not statistically different from each other. Complementary to the previous "variable specific" performance assessment, overall simulations were evaluated using Model II regression analyses (Standardized Major Axis regression-SMA using the software SMATR 3.0; Warton et al., 2012). The Model II regression 95\% confidence limits for intercept and slope were determined for each analysis to assess the averaged Model_LULC/Model_FG proximity in relation to the respective averaged Real_LULC/Real_FG (Sokal and Rohlf, 1995). The StDM simulations and predictions were considered accurate when (1) a statistically significant correlation occurred between both sets of data; (2) the intercept of the common regression line was not statistically significantly different from 0 ; and (3) the common regression slope line was not statistically significantly different from 1 (Sokal and Rohlf, 1995; Warton et al., 2012).

\section{Results}

3.1. General results: land use/land cover and passerine guilds monitored in 2017

The dominant LULC monitored in 2017 (Real_LULC) were olive and almond orchards (Ola), cereals and fallows (Cfa) and Shrublands (Shr) (Appendixes A and B). We recorded 31 passerine species, distributed in 11 arboreal insectivorous, 7 arboreal granivorous, 7 pseudo steppe insectivorous and 6 pseudo steppe granivorous (Appendixes B and C).

\subsection{StDM simulations and predictions}

The decline of cereal and fallow (Cfa) areas, through a conversion to olive and almond orchards (Ola) was originally assumed as the main trend in the modelled landscape (Model_LULC) (Appendixes E-G). This scenario predicted changes in the functional guilds richness (Model_FG): arboreal guilds were expected to increase while pseudo-steppe guilds were expected to decrease in most plots. Independent data were obtained for 2017 concerning the landscape characterization (Real_LULC) and the passerine community functional composition 
(Real_FG). Appendix D depicts model simulations for 2017 (Model_LULC and Model_FG) and the respective real monitored data in 2017 (Real_LULC and Real_FG).

\subsection{StDM framework performance}

\subsubsection{Simulated versus real land use/land cover for 2017}

To evaluate the StDM scenarios credibility, the simulated changes in the landscape composition, as published thirteen years ago, were compared with current landscape characteristics in the same study area. Concerning LULC simulations for 2017, the confrontation between each Model_LULC and the respective Real_LULC were not statistically significantly different (Table 1): "+ " represents accurate predicted simulations. The averaged Model_LULC versus the averaged Real_LULC confirmed the previous consistent patterns simulated (Table 2).

Table 1

Wilcoxon test for comparisons between simulated proportions of Land use/Land cover (M_LULC) for 2017 and real percentages LULC monitored in 2017 (R_LULC) by plot. Number of plots used for comparisons (N), Wilcoxon value (V) and median differences between simulated and real data $(\Delta \mathrm{M})$ and significance level (n.s. - non significant). "Accuracy" summarizes the LULC matching performance either when accurately predicted "+" or inaccurately predicted "-" by the StDM model. Variables explanation available in Appendix B.

\begin{tabular}{lllll}
\hline LULC & $\mathrm{N}$ & $\mathrm{V}$ & $\Delta \mathrm{M}$ & Accuracy \\
\hline Cfa & 22 & 141 & 0.022154 (n.s.) & + \\
Cor & 22 & 9 & 0 (n.s.) & + \\
Fru & 22 & 0 & 0 (n.s.) & + \\
Ola & 22 & 128 & 0.028822 (n.s) & + \\
Oth & 22 & 31 & -0.009996 (n.s.) & + \\
Pas & 22 & 3 & 0 (n.s) & + \\
Riv & 22 & 70 & 0 (n.s.) & + \\
Shr & 22 & 109 & -0.012004 (n.s.) & + \\
Urb & 22 & 30 & 0 (n.s.) & + \\
Veg & 22 & 6 & 0 (n.s.) & + \\
Vin & 22 & 155 & 0.00702 (n.s.) & + \\
\hline
\end{tabular}

\subsubsection{Predicted versus monitored functional guilds' richness for 2017}

To evaluate guilds response consistency, predicted effects of landscape changes on richness of functional guilds (FG), as published thirteen years ago, was compared with current FG richness recorded in 2017. Concerning the passerines functional guilds' richness (FG) predicted for 2017, most simulations (Model_FG) were not statistically significantly different from real data obtained in 2017 (Real_FG) (Table 3): “+" represents accurate simulations while "-" represents inaccurate simulations. With the exception of Arboreal Insectivorous (Ain), a very good model performance was obtained for the remaining passerine functional groups (Table 3 ) and a consistent pattern at the community level seemed to be easily recognized from the overall predictions supported by the Model II results (Table 4).

Table 2

Standardized Major Axis regression (SMA) for comparisons between simulated proportions for each LULC (M_LULC) and monitored proportions for each LULC (R_LULC) for 2017. Coefficients of determination $\left(\mathrm{R}^{2}\right)$ and their significance level $\left({ }^{* * * *}-\mathrm{p}<0.001\right)$. The common line intercepts ( $95 \%$ confidence limits in parentheses) and difference from 0 verification: T-value (n.s. $-\mathrm{p}>0.05$ ). The common line slope ( $95 \%$ confidence limits in parenthesis) and verification of difference from 1: F-value (n.s. $-\mathrm{p}>0.05$ ).

\begin{tabular}{lllllll}
\hline Variable & $\mathrm{N}$ & $\mathrm{R}^{2}$ & Intercept & T-value & Slope & F-value \\
\hline LULC & \multirow{2}{*}{11} & $0.994^{\text {***k }}$ & $\begin{array}{l}0.004(-0.006 ; \\
0.014)\end{array}$ & $\begin{array}{l}0.867 \\
\text { (n.s.) }\end{array}$ & $\begin{array}{l}0.961 \\
(0.906 ; 1.02)\end{array}$ & $\begin{array}{l}2.147 \\
\text { (n.s.) }\end{array}$
\end{tabular}

Table 3

Wilcoxon test for comparisons between predicted functional guild richness (M_FG) for 2017 and real functional guild richness (R_FG) recorded in 2017 by bird point counts. Number of point counts used for comparisons (N), Wilcoxon value $(\mathrm{V})$ and median differences between simulated and real FGR $(\Delta M)$ and significance level $\left(^{* * *}-\mathrm{p}<0.01\right.$, n.s. - non significant). "Accuracy" summarizes the FG matching performance either when accurately predicted "+" or inaccurately predicted " - " by the StDM model. Variables explanation available in Appendix B.

\begin{tabular}{lllll}
\hline Functional group (FG) & $\mathrm{N}$ & $\mathrm{V}$ & $\Delta \mathrm{M}$ & Accuracy \\
\hline Agr & 22 & 168 & 0.2918845 (n.s) & + \\
Ain & 22 & 207 & $0.705465\left(^{* *}\right)$ & - \\
Pgr & 22 & 107 & -0.3614802 (n.s.) & + \\
Pin & 22 & 149 & 0.256722 (n.s.) & + \\
\hline
\end{tabular}

Table 4

Standardized Major Axis regression (SMA) for comparisons between simulated richness for each functional guild (M_FG) and monitored richness (R_FG) (total richness was also considered), for 2017. Coefficients of determination $\left(\mathrm{R}^{2}\right)$ and their significance level $\left({ }^{k *}-\right.$ $\mathrm{p}<0.01)$. Common line intercepts $(95 \%$ confidence limits in parentheses) and difference from 0 verification: T-value (n.s. $-\mathrm{p}>0.05$ ). The common line slope ( $95 \%$ confidence limits in parenthesis) and verification of difference from 1: F-value (n.s. $\mathrm{p}>0.05)$.

\begin{tabular}{lllllll}
\hline Variable & $\mathrm{N}$ & $\mathrm{R}^{2}$ & Intercept & T-value & Slope & F-value \\
\hline FG & 5 & $0.975^{* * *}$ & $\begin{array}{l}0.138(-1.326 ; \\
1.602)\end{array}$ & $\begin{array}{l}0.300 \\
\text { (n.s.) }\end{array}$ & $\begin{array}{l}1.195(0.897 ; \\
1.591)\end{array}$ & $\begin{array}{l}3.834 \\
\text { (n.s.) }\end{array}$ \\
\hline
\end{tabular}

\section{Discussion}

\subsection{Landscape changes and functional guilds' response}

To detect the effects of social-environmental change on the structure and functioning of ecological systems, birds have been widely used as indicators of biodiversity and ecological integrity. In fact birds occur in relatively high densities and diversity, can be easily monitored, and crowdsourcing data are often available (e.g., Morelli et al., 2015). Birds are also highly sensible to LUCC and, for many species demography, behaviour, distribution and phenology are linked with agroecosystems management (Santos and Cabral, 2004). In the study region, biological communities and passerine communities in particular are characterized by a combination of pseudo-steppe species, mostly associated with open habitats and generalist "arboreal" species that have broader niches and are mostly Eurasian (Santos et al., 2016b). As predicted by the Santos and Cabral (2004) simulations, intensive orchards had a positive effect on the occurrence of arboreal guilds and a negative effect on Mediterranean pseudo-steppe guilds, stressing the importance of the traditional landscape patchwork layout for conservation of biodiversity (Bastos et al., 2016). Commonly reported impacts of intensive plantations such as permanent crops in mixed agricultural landscapes include resources depletion, intrusion of edge effects in natural areas, isolation/ barrier effects for some species and increased human access and disturbance (Santos et al., 2016b). In order to support our findings, more studies are needed, including improved quantifications of the relationships between indicators, agroecosystem functioning and overall diversity, which is currently not fully understood or recognized (e.g., Gao et al., 2015). Therefore, we highlight the importance of broadening the analysis to other seasons, namely winter when habitat selection can be different and using complementary information to assess the real extent of land use/land cover changes (LUCC) and its ecological impacts (Atkinson et al., 2002; Morinha et al., 2017). These developments would add up to the current holistic model/framework evaluated, contributing to produce an integrative methodology for estimating effects of landscape changes on passerine populations and in the ecological integrity of this agroecosystem. 


\subsection{Evaluation of the StDM performance for rural landscapes}

The fundamental objective guiding this StDM application was to minimize inherent dynamic modelling implementation problems such as parameterisation, model complexity and variables choice (Santos and Cabral, 2004; Santos et al., 2013). Our model falls into the category of the so-called hybrid models (Chen et al., 2011), i.e., modelling species distributions on the basis of large-scale holistic relationships (e.g., rural landscape dynamics) while at the same time considering the most important fine-scale processes (e.g., dependence on specific LULC). This is one of the major advantages of this type of models (Santos et al., 2013): combining different approaches and enabling information crossing at a local scale, allowing for a better understanding of rural landscape dynamics, and leading to emergence and complex system characteristics (Santos et al., 2013, 2016a). If we consider that validation is a fundamental process to prove model applicability, our results demonstrate that the trends in the landscape composition and guilds richness were in general captured with credibility by the Santos and Cabral (2004) work. The StDM accuracy in capturing ecological changes is ultimately linked with the quality of the data-base, namely regarding the gradient of representative environmental conditions with influence on the target response variables (Santos et al., 2013). Specific papers covered aspects of model usefulness, with very special attention given to the evaluation and testing (Rykiel, 1996). Our model was evaluated using chronosequential information coupled to standard statistical techniques, such as non-parametric comparative tests (e.g., Wilcoxon) and Model II regression (Sokal and Rohlf, 1995) where model simulations were compared with the correspondent values monitored in the field. Although this validation method could be considered incomplete, not judging the StDM conceptualization and preconceptions, we consider that the most significant step for a model usefulness is the "realism" in the obtained results, i.e., robust validation using independent field data is essential for the strategic decisionmaking in rural landscapes (Rykiel, 1996).

\subsection{Implications for biodiversity conservation in rural landscapes}

Climate and socio-ecological pressures constrain disturbance regimes shaping agricultural landscapes, even though with impacts only partially understood (e.g., Fernandes et al., 2013). Conversely, environmental policies and strategies should be linked with planning decisions and projections of possible outcome scenarios (Santos et al., 2013). Thus, it is fundamental to characterize and understand the main cause-effect relationships between changes in the landscape and ecosystem responses (Santos et al., 2016b). Enhancing and/or maintaining biodiversity and the ecosystem services can be the basis for adapting the rural landscapes to global and regional changes, as well as to the design of risk-decreasing strategies as they can deliver benefits that will increase the resilience of socio-ecological systems (Larigauderie and Mooney, 2010). For example, agricultural intensification (as well as the abandonment of agriculture) may drive many rural systems into alternative states with reduced ecosystem services, difficult to reverse because of the long-time lags characterizing the dynamics of socio-ecological systems (Figueiredo and Pereira, 2011). In fact societal and ecological mechanisms usually interact, generating changes in biological communities, degradation of ecosystem services and effects on human well-being in an imperceptible and misunderstood way (Bennett et al., 2009). Our study aimed to inform decision makers about outcomes of biodiversity, helping the implementation of local conservation actions: LULC patterns simulated and the predicted changes in the guilds' richness were globally accurate, stressing the importance of landscape patchwork for conservation (Santos et al., 2016b). The validation of the modelling results could be used to support strategic thinking about local landscape planning and the guidance of environmental/agriculture policies and investments (Morinha et al., 2017; Silva et al., 2017). We have focused this study on gauging a specific scenario and region, recognizing that processes of planning and management involve multiple social and ecological objectives that differ between location and context (Figueiredo and Pereira, 2011). In the studied region, landscape management actions and planning assessments designed for biodiversity conservation should focus on the maintenance of the traditional agricultural mosaic. This strategy can contribute to maintaining a diversity of land use/land cover in a heterogeneous landscape, fundamental for the implementation, at a local scale, of national biodiversity strategies and action plans (Bastos et al., 2016; Santos et al., 2016b).

\section{Conclusions}

Regarding priority species, as most pseudo-steppe passerines that depend on traditional agriculture, this study highlights the conflicts between conservation efforts and agriculture policies (Phalan et al., 2011). Therefore, we consider that investment and management policies for agriculture in Europe should take into consideration modelling results in selecting appropriate actions to avoid deterioration of agroecosystems and associated biodiversity (Phalan et al., 2011). The obtained results are also quite inspiring, considering the time-lag between the model conceptions and simulations - 2001/2002 - and real data used for comparisons - 2017. Our framework evaluation demonstrated that StDM models might support decisions, namely as a management tool for testing the implementation of agro-environmental schemes, improving the current situation where results of previous studies on ecological directives or estimated impacts are barely taken into account (Stoate et al., 2009). Additionally, the development of ecosystem change assessment methodologies must take into account the application's viability and if the results can be applied to other areas of interest (Andreasen et al., 2001). Actually, the proposed methodological principles can be easily adjusted or adapted to other species, contexts and landscapes. This type of framework may provide a basis for decision-making regarding permitting and mitigation prior to land use changes, when few other tools are available. Overall, our approach can underpin landscape management and policy decisions in agricultural landscapes assuring ecosystems services/conservation of wildlife in the face of ongoing environmental changes.

\section{Acknowledgements}

This work is supported by: Laboratory of Applied Ecology of the University of Trás-os-Montes e Alto Douro Funds, European Investment Funds by FEDER/COMPETE/POCI - Operational Competitiveness and Internationalization Program, under Project POCI-01-0145-FEDER006958 and National Funds by FCT - Portuguese Foundation for Science and Technology, under the project UID/AGR/04033/2013. RB is supported by FCT through the PhD grant SFRH/BD/102428/2014.

\section{Appendix A. Supplementary data}

Supplementary data associated with this article can be found, in the online version, at http://dx.doi.org/10.1016/j.ecolind.2018.03.023.

\section{References}

Andreasen, J.K., O’Neill, R.V., Noss, R., Slosser, N.C., 2001. Considerations for the development of a terrestrial index of ecological integrity. Ecol. Indic. 1 (1), 21-35. Atkinson, P.W., Fuller, R.J., Vickery, J.A., 2002. Large-scale patterns of summer and winter bird distribution in relation to farmland type in England and Wales. Ecography 25 (4), 466-480.

Bastos, R., D’Amen, M., Vicente, J., Santos, M., Yu, H., Eitelberg, D., Gonçalves, J., Civantos, E., Honrado, J., Cabral, J.A., 2016. A multi-scale looping approach to predict spatially dynamic patterns of functional species richness in changing landscapes. Ecol. Indic. 64, 92-104.

Bennett, E.M., Peterson, G.D., Gordon, L.J., 2009. Understanding relationships among multiple ecosystem services. Ecol. Lett. 12 (12), 1394-1404.

Bugalho, M.N., Caldeira, M.C., Pereira, J.S., Aronson, J., Pausas, J.G., 2011. 
Mediterranean cork oak savannas require human use to sustain biodiversity and ecosystem services. Front. Ecol. Environ. 9 (5), 278-286.

Chen, Q., Han, R., Ye, F., Li, W., 2011. Spatio-temporal ecological models. Ecol. Inf. 6 (1), 37-43.

Evans, M.R., Grimm, V., Johst, K., Knuuttila, T., De Langhe, R., Lessells, C.M., Merz, M., O'Malley, M.A., Orzak, S.H., Weisberg, M., Wilkinson, D.J., Wolkenhauer, O., Benton, T.G., 2013. Do simple models lead to generality in ecology? Trends Ecol. Evol. 28 (10), 578-583.

Fernandes, C., Cabral, J.A., Crespí, A.L., Hughes, S.J., Santos, M., 2013. Converting simple vegetation surveys in functional dynamics. Acta Oecol. 48, 37-46.

Figueiredo, J., Pereira, H.M., 2011. Regime shifts in a socio-ecological model of farmland abandonment. Landscape Ecol. 26 (5), 737-749.

Gao, T., Nielsen, A.B., Hedblom, M., 2015. Reviewing the strength of evidence of biodiversity indicators for forest ecosystems in Europe. Ecol. Indic. 57, 420-434.

Jørgensen, S.E., 2008. Overview of the model types available for development of ecological models. Ecol. Modell. 215 (1), 3-9.

Larigauderie, A., Mooney, H.A., 2010. The intergovernmental science-policy platform on biodiversity and ecosystem services: moving a step closer to an IPCC-like mechanism for biodiversity. Curr. Opin. Environ. Sustain. 2 (1), 9-14.

Lomba, A., Alves, P., Jongman, R.H., McCracken, D.I., 2015. Reconciling nature conservation and traditional farming practices: a spatially explicit framework to assess the extent of High Nature Value farmlands in the European countryside. Ecol. Evol. 5 (5), 1031-1044.

Morelli, F., Jiguet, F., Reif, J., Plexida, S., Valli, A.S., Indykiewicz, P., Šímová, P., Tichit, M., Moretti, M., Tryjanowski, P., 2015. Cuckoo and biodiversity: testing the correlation between species occurrence and bird species richness in Europe. Biol. Conserv. 190, 123-132.

Morinha, F., Bastos, R., Carvalho, D., Travassos, P., Santos, M., Blanco, G., Bastos, E., Cabral, J.A., 2017. A spatially-explicit dynamic modelling framework to assess habitat suitability for endangered species: the case of Red-billed Chough under land use change scenarios in Portugal. Biol. Conserv. 210, 96-106.

Phalan, B., Onial, M., Balmford, A., Green, R.E., 2011. Reconciling food production and biodiversity conservation: land sharing and land sparing compared. Science 333 (6047), 1289-1291.

Rykiel, E.J., 1996. Testing ecological models: the meaning of validation. Ecol. Modell. 90
(3), 229-244.

Santos, M., Cabral, J.A., 2004. Development of a stochastic dynamic model for ecological indicators' prediction in changed Mediterranean agroecosystems of north-eastern Portugal. Ecol. Indic. 3 (4), 285-303.

Santos, M., Bastos, R., Cabral, J.A., 2013. Converting conventional ecological datasets in dynamic and dynamic spatially explicit simulations: current advances and future applications of the Stochastic Dynamic Methodology (StDM). Ecol. Modell. 258, 91-100.

Santos, M., Bessa, R., Cabral, J.A., Pacheco, F.A.L., Leitao, D., Moreira, F., Pinto, M., Lecoq, M., Silva, J.P., 2016a. Impacts of land use and infrastructural changes on threatened Little Bustard Tetrax tetrax breeding populations: quantitative assessments using a recently developed spatially explicit dynamic modelling framework. Bird Conserv. Int. 26 (4), 418-435.

Santos, M., Ferreira, D., Bastos, R., Vicente, J., Honrado, J., Kueffer, C., Kull, C.A., Berger, U., Cabral, J.A., 2016b. Linking landscape futures with biodiversity conservation strategies in northwest Iberia-a simulation study combining surrogates with a spatio-temporal modelling approach. Ecol. Inf. 33, 85-100.

Schmolke, A., Thorbek, P., DeAngelis, D.L., Grimm, V., 2010. Ecological models supporting environmental decision making: a strategy for the future. Trends in Ecol. Evol. 25 (8), 479-486.

Silva, C., Cabral, J.A., Hughes, S.J., Santos, M., 2017. A modelling framework to predict bat activity patterns on wind farms: an outline of possible applications on mountain ridges of North Portugal. Sci. Total Environ. 581, 337-349.

Sokal, R.R., Rohlf, F.J., 1995. Biometry, third ed. WH Freman and Company, New York. Stoate, C., Báldi, A., Beja, P., Boatman, N.D., Herzon, I., Van Doorn, A., de Snoo, G.R., Rakosy, L., Ramwell, C., 2009. Ecological impacts of early 21st century agricultura change in Europe - a review. J. Environ. Manage. 91 (1), 22-46.

Van Eetvelde, V., Antrop, M., 2004. Analyzing structural and functional changes of traditional landscapes - two examples from Southern France. Landscape Urban Plan. 67 (1), 79-95.

Warton, D.I., Duursma, R.A., Falster, D.S., Taskinen, S., 2012. smatr 3 - an R package for estimation and inference about allometric lines. Methods Ecol. Evol. 3 (2), 257-259.

Wilcoxon, F., 1945. Individual comparisons by ranking methods. Biometrics Bull. 1 (6), 80-83. 